\title{
OCORRÊNCIA DE Enterococcus faecalis EM INFECÇÕES PULPARES E AVALIAÇÃO DA SENSIBILIDADE A ANTIMICROBIANOS
}

\section{OCCURENCE STUDY OF Enterococcus faecalis IN PULP INFECTIONS AND EVALUATION OF SENSITIVITY TO ANTIMICROBIAL}

\author{
Wanderley Agnaldo Pinto ${ }^{1}$ \\ Edson Penha Filho \\ Mario Lúcio Jardim Parreira ${ }^{3}$ \\ Jorge Kleber Chavasco ${ }^{4}$
}

\begin{abstract}
${ }^{1}$ Mestre- Cirurgião Dentista- Especialista em Odontopediatria
${ }^{2}$ Mestre- Cirurgião Dentista- Especialista em Endodontia

${ }^{3}$ Doutor- Cirurgião Dentista- Professor Titular Aposentado da Universidade Federal de Minas Gerais (UFMG)

${ }^{4}$ Doutor-Professor Associado de Microbiologia da Universidade Federal de Alfenas (UNIFAL-MG) - Alfenas- MG Brasil
\end{abstract}

Autor Correspondente:

Prof. Dr. Jorge Kleber Chavasco

Universidade Federal de Alfenas (UNIFAL-MG)

Rua Gabriel Monteiro da Silva 700

37130-000- Alfenas-MG-Brasil

Email: jkchavasco@uol.com.br

RESUMO: Considerando a alta incidência de Enterococcus faecalis em infecções endodônticas refratarias ao tratamento e a sua resistência a vários antimicrobianos, julgamos oportuna a realização de pesquisa para avaliar a sua presença nestas infecções. Para tanto foram selecionados 77 pacientes, portadores de patologias pulpares irreversíveis, dos quais foram coletadas amostras para cultura em laboratório. Os resultados obtidos nos mostraram que 13 amostras (11 amostras provenientes de canal radicular e 02 de câmara pulpar) apresentaram E. faecalis. Quanto ao antibiograma todas amostras de E. faecalis mostraram-se sensíveis a vancomicina e gentamicina 120, porem todas se mostraram resistentes a gentamicina 10 , ciprofloxacin, clindamicina e cefalotina.

Palavras -chaves: Enterococcus faecalis. infecção pulpar. antibiograma. infecção endodontica. canais radiculares

\begin{abstract}
Thinking over high incidence of Enterococcus faecalis in refractary endodontic infections at treatment and their resistance to several antimicrobial, we think opportune carriyng out of search for evaluate their presence in these infections. For this 77 patients were selected, bearing irreversible pulp pathology, which samples were collected for laboratory culture. Results obtained showed us that 13 samples (11 samples from root canal and 02 samples from pulp chamber) introduced E. faecalis. As for antibiogram all of samples of E. faecalis showed sensitivity to vancomicin and gentamicin 120, but all samples showed resistant to gentamicin 10, ciprophloxacin, clindamicin and cephalotin
\end{abstract}

Key words: Enterococcus faecalis, pulp infection. antibiogram. endodontic infection. roots canals 


\section{INTRODUÇÃO}

As bactérias são as principais causadoras das doenças da polpa dentária e dos tecidos periapicais. Por isso, o conhecimento dessas bactérias e as suas características que possibilitam-nas sobreviverem ou não no endodonto podem servir para melhorar o julgamento clínico do profissional no tratamento das infecções pulpares e periapicais. Os enterococos, que compõe a microbiota normal da cavidade oral, são bactérias de alta prevalência em infecções pulpares persistentes e apresenta um perfil de resistência a antibióticos bastante variado (De Deus,1992, Oliveira et. al. 2001). Inicialmente o termo Enterococcus foi utilizado para designar Streptococcus que cresciam em temperaturas entre $10^{\circ} \mathrm{C}$ e $45^{\circ} \mathrm{C}$, em $6,5 \%$ de $\mathrm{NaCl}$ e hidrolisavam a esculina na presença de $40 \%$ de sais biliares. Porem em 1984 , baseado nas diferenças genéticas, os Enterococcus foram retirados do gênero Streptococcus, sendo criado um gênero à parte, designado Enterococcus. Conseqüentemente a espécie passaria a ser designada de Enterococcus faecalis (Facklam et. al,1999).

Noda et al (2000) testaram a suscetibilidade a antibióticos das bactérias detectadas do exudato de canal radicular com periodontite apical presente. Foram realizados 15 testes em pacientes que, após cultura bacteriana, revelou ser Enterococcus a espécie mais freqüentemente isolada nos casos de retratamento de periodontite apical, embora seja também detectada em infecções primárias. Enterococcus faecalis raramente é encontrado nos casos de infecções primárias mas em casos de retratamento é a espécie predominante chegando a representar de $38 \%$ a $70 \%$ da microbiota nesses casos, ( Maia Filho, 2008)

Goldman et al. (1969) realizaram exames microbiológicos de canais radiculares pós debridamento em 563 casos e avaliaram a sensibilidade a anti-sépticos trocando o curativo a cada visita. Enterococcus sp foi o organismo mais persistente, permanecendo em 32\% dos canais Quanto ao antibiograma, os testes de sensibilidade antibiótica mostraram que o novobiocina é o mais eficaz, seguido da penicilina, eritromicina, tetraciclina. Miranda (1969) verificou que dentre as espécies isoladas de infecções de canais radiculares refratários aos tratamentos, os enterococos foram os mais resistentes aos antibióticos e anti-sépticos testados

Nord et al. (1973) realizaram um estudo com 92 tipos de enterococos hemolíticos isolados de infecções orais, para que sua suscetibilidade a oito antibióticos pudesse ser avaliada in vitro. Todos os tipos eram altamente sensíveis a azidocilina e a ampicilina. A maioria era sensível a eritromicina, enquanto $70 \%$ eram sensíveis a tetraciclina. Todos os tipos eram resistentes ao cefalexina. 
Zebral et al. (1994) verificaram a incidência de Enterococcus em canais dentários infectados, após pelo menos uma sessão de biomecânica e um curativo de demora, com uma incidência de 29 testes positivos em 100 testes realizados.

Relatos na literatura ressaltam a importância atribuída aos enterococos, sendo considerado o mais resistente dos microrganismos frente à ação de agentes antibacterianos normalmente empregados em endodontia.

\section{MATERIAL E MÉTODO}

Inicialmente o projeto deste trabalho foi submetido ao Comitê de Ética em Pesquisa da UNINCOR. Foram selecionados 77 pacientes da Clinica Odontológica da UNINCOR (Universidade Vale do Rio Verde de Três Corações), portadores de comprometimento pulpar irreversível, no período de agosto a setembro de 1999, ignorando-se o estado do dente e da polpa, a faixa etária, o nível sócio econômico, a raça, a cor e o sexo, dos quais foram coletadas 52 amostras de canal radicular e 25 de câmara pulpar. Previamente os pacientes assinaram o termo de consentimento esclarecido, autorizando a coleta de material. Utilizou-se na coleta do material para isolamento de Enterococcus faecalis, cones de papel número 25 (Tanari) e "swabs" para coleta no canal radicular e câmara pulpar respectivamente, esterilizados em autoclave. A coleta foi realizada após o isolamento absoluto do dente com dique de borracha e abertura da câmara pulpar. Em seguida, as amostras foram inoculadas em tubos contendo caldo Tioglicolato (Merck), e incubadas a $37^{\circ} \mathrm{C}$ por 48 horas conforme metodologia preconizada por De Deus (1992). A partir do crescimento bacteriano no referido meio, as bactérias foram transferidas para uma placa contendo Agar bile esculina (Merck) e incubadas a $37^{\circ} \mathrm{C}$ por 48 horas para isolamento de Enterococcus faecalis. As amostras isoladas foram submetidas ao método de Gram e a prova da catalase (Santos Filho,1996).

O teste de sensibilidade a antibióticos foi realizado pela técnica de Bauer et al. (1966) em placas de Petri contendo Agar Mueller Hinton (Merck), utilizando-se os discos de papel da marca CECON contendo os seguintes antibióticos: amoxicilina, cefalotina, ciprofloxacin, claritromicina, clindamicina, cloranfenicol, sulfazotrim, tetraciclina e vancomicina, tobramicina, gentamicina 10 e gentamicina 120 .

\section{RESULTADOS}

Das 77 amostras coletadas e pesquisadas, $13(16,88 \%)$ foram positivas para Enterococcus faecalis, sendo 11 amostras $(14,28 \%)$ de canal radicular e 2 amostras $(2,59 \%)$ de câmara pulpar. 
Em relação ao antibiograma, verificou-se que apenas os antimicrobianos vancomicina e gentamicina 120 se mostraram eficazes em todas as amostras. A gentamicina 10, clindamicina, cefalotina e ciprofloxacin não foram eficazes em nenhuma das amostras de E. faecalis.

A amoxicilina foi eficaz em 11 amostras (84,61\%). Quanto aos demais antimicrobianos testados, a claritromicina e tetraciclina foram eficazes em 3 amostras $(23,07 \%)$. A tobramicina e cloranfenicol mostraram-se eficazes em 7 amostras $(53,84 \%)$ e o sulfazotrim em 2 amostras $(15,38)$. Estes dados encontram-se na Tabela 01 e Figura 01.

TABELA 01 - Resultados, em percentual, da sensibilidade e resistência aos antimicrobianos de 13 amostras de $E$. faecalis.

\begin{tabular}{|c|c|c|c|c|}
\hline \multirow[t]{3}{*}{ ANTIMICROBIANOS } & \multicolumn{3}{|c|}{ AVALIAÇÃO } & \multirow[b]{3}{*}{$\%$} \\
\hline & \multicolumn{2}{|l|}{ Sensível } & Resistente & \\
\hline & $\mathrm{N}^{\mathrm{o}}$ de amostras & $\%$ & $\mathrm{~N}^{\mathrm{o}}$ de amostras & \\
\hline Amoxicilina & 11 & 84,6 & 2 & 15,4 \\
\hline Cefalotina & 0 & 0 & 13 & 100,0 \\
\hline Ciprofloxacin & 0 & 0 & 13 & 100,0 \\
\hline Claritromicina & 3 & 23,0 & 10 & 77,0 \\
\hline Clindamicina & 0 & 0 & 13 & 100,0 \\
\hline Cloranfenicol & 7 & 53,8 & 6 & 46,2 \\
\hline Gentamicina 10 & 0 & 0 & 13 & 100,0 \\
\hline Gentamicina 120 & 13 & 100,0 & 0 & 0 \\
\hline Sulfazotrim & 2 & 15,4 & 11 & 84,6 \\
\hline Tetraciclina & 3 & 23,0 & 10 & 77,0 \\
\hline Tobramicina & 7 & 53,8 & 6 & 46,2 \\
\hline Vancomicina & 13 & 100,0 & 0 & 0 \\
\hline
\end{tabular}

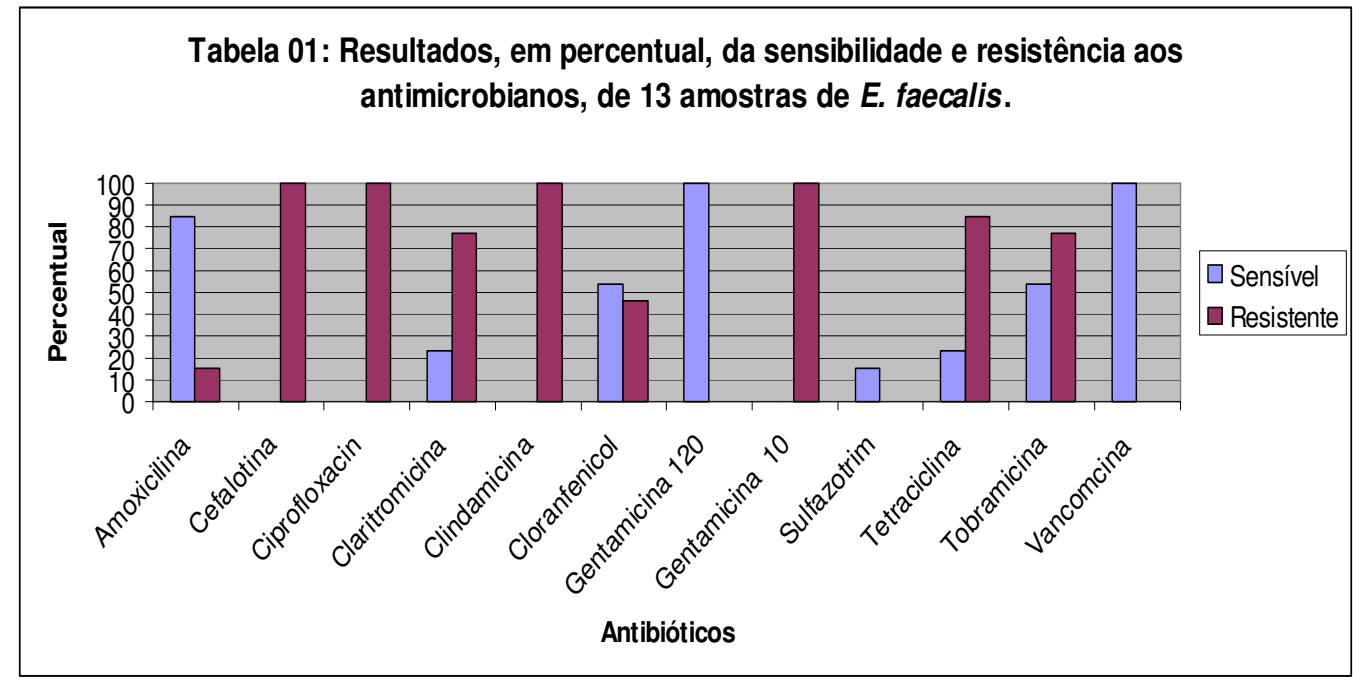




\section{DISCUSSÃO}

Uma das bactérias mais prevalentes em canais contaminados, depois das bactérias dos gêneros Porphyromonas e Prevotella, são os Enterococcus faecalis (Berger et al,1998).

Enterococcus faecalis tem significativa importância endodôntica, pois estes possuem resistência inerente a agentes antimicrobianos que se não controlados podem ser favorecidos pela alteração nas condições ecológicas dos canais radiculares e estabelecer um processo infeccioso de difícil tratamento. E. faecalis esta sempre relacionado ao insucesso no tratamento endodôntico, (Estrela ,1999).

Noda et. al. (2000) pesquisaram a presença de Enterococcus em infecções pulpares. Verificou-se que apenas 2 das 19 espécies identificadas atualmente são responsáveis por infecções em humanos: Enterococcus faecalis e Enterococcus faecium.

Das 77 amostras coletadas e pesquisadas em nosso trabalho, 13 (16,88\%) foram positivas para Enterococcus faecalis, sendo 11 amostras $(14,28 \%)$ de canal radicular e 2 amostras $(2,59 \%)$ de câmara pulpar. Autores como Grossmam encontraram uma prevalência de 5\% nos canais infectados e Winkler encontrou E. faecalis em $19 \%$ dos canais examinados (Weine 1998).

Os Enterococcus também são naturalmente resistentes as cefalosporina, às penicilinas semi-sintéticas resistentes as penicilinases, a clindamicina, as quinolonas, aos carbapenens e ao sulfametaxazoltrimetoprim (sulfazotrim), Oliveira et al, (2001). No presente trabalho verificamos que todas as amostras testadas foram resistentes a clindamicina, cefalotina e ciprofloxacin. Das 13 amostras testadas, 2 foram sensíveis ao sulfazotrim, dados estes coerentes com os encontrados na literatura.

A presença de altos níveis de resistência aos aminoglicosídeos representa um sério problema terapêutico, pois acarreta a perda do efeito sinérgico com $\beta$-lactâmicos e glicopeptídeos. No nosso trabalho encontramos todas amostras resistentes a gentamicina 10 porem todas foram sensíveis a gentamicina 120 .

Heintz et al. (1975) relataram em estudo a sensibilidade de Enterococcus que permaneceram nos canais mesmo depois de tratamento. Todas as amostras isoladas foram identificadas como Enterococos faecalis ou uma de suas variedades. Os 50 tipos testados eram sensíveis a ampicilina e a vancomicina. Todos eles eram resistentes a estreptomicina e às sulfas.

No Brasil o isolamento de Enterococcus resistentes a vancomicina foi relatado em vários hospitais e sua freqüência de isolamento continua aumentando gradativamente (Oliveira et. al. 2001). Neste trabalho todas as amostras mostraram-se sensíveis a vancomicina sendo estes 
resultados semelhantes ao encontrados por Zebral (1994).

A resistência de E. faecalis aos antibióticos pode favorecer determinados processos infecciosos ou mesmo complica-los pois esta bactéria é detectada em $14 \%$ dos casos de endocardite bacteriana e o tratamento endodôntico pode ser responsável por 17 a $100 \%$ dos casos de bacteremia (Berger et al 1998) o que poderia desencadear endocardite bacteriana com as amostras resistentes aos antibióticos de uso profilático como a amoxicilina. No nosso trabalho a amoxicilina foi eficaz em $84,61 \%$ das amostras testadas.

Noda et al (2000), realizaram testes de sensibilidade a antibióticos de amostras detectadas do exudato de canais radiculares com periodontite apical. Após cultura bacteriana, revelou ser o Enterococcus a espécie mais freqüentemente isolada e sua resistência a cefalosporina, como a cefalotina testada neste experimento e também com o mesmo perfil de resistência. Dentre os aminoglicosídeos testados a tobramicina mostrou efetividade em 53,8\% das amostras testadas ao contrario da gentamicina 10 que não foi efetiva em nenhuma das amostras dados semelhantes aos encontrados por Zebral (1994). A tetraciclina e cloranfenicol são indicadas como segunda opção no tratamento das infecções enterocócicas porem no nosso trabalho somente o cloranfenicol mostrou-se efetivo em 53,8\% das amostras testadas dados semelhantes aos resultados obtidos por Zebral
(1988) e Miranda (1969). Claritromicina apesar de ser recomendada em infecções por enterococos (Lopes 2000), no presente trabalho das 13 amostras testadas somente 3 $(23,0 \%)$ apresentaram sensibilidade ao referido antibiótico.

Como o perfil de sensibilidade das amostras de E. faecalis aos antibióticos ser bastante variado, os critérios de escolha para uso profilático de antibiótico na endocardite bacteriana deveria ser revisto apesar de $84,6 \%$ das amostras testadas serem sensíveis a amoxicilina que é o antibiótico recomendado pela AHA (American Heart Association) (1997).

\section{CONCLUSÃO}

Com os resultados obtidos neste trabalho conclui-se que o Enterococcus faecalis foi encontrado em $13(16,88 \%)$ das 77 amostras coletadas, sendo 11 amostras $(14,28 \%)$ de canal radicular e 2 amostras $(2,59 \%)$ de câmara pulpar. Quanto ao teste de sensibilidade a antimicrobianos, a amoxicilina, vancomicina e gentamicina 120 mostraram ser os antimicrobianos mais eficazes frente a amostras de Enterococcus faecalis pesquisadas bem como a gentamicina 10, clindamicina, cefalotina e ciprofloxacin mostraram-se ineficazes 


\section{REFERÊNCIAS}

1. AHA, American Heart Association, JAMA: 227, 1796-1801, 1997.

2. BAUER, A.M. et al. Antibiotic suscebility by a standardized singler a dick method. American Journal of Clinical Pathology. v.45, p.493-496, 1966.

3. BERGER, C.R. et. al. Endodontia. São Paulo : Ed. Pancast, 1998.

4. DE DEUS, Q. D. Endodontia. São Paulo:Ed. MEDSI, 1992.

5. ESTRELA, C. Endodontia, princípios biológicos e mecânicos. São Paulo: Artes Medicas, 1999.

6. FACKLAM R.R.; SAHM D.F.; TEIXEIRA, A.L.M. Enterococcus .In: MURRAY, P.R. et al. Manual of Clinical microbiology. 7 ed. Washington, Edition ASM Press, 1999.

7. GOLDMAN,M. et al. Post debridement bacterial flora and antibiotic sensibility.

Oral Sugery, Oral Medicine, Oral Radiology and Endodontics. v. 28, n.6, p.897-905, 1969.

8. LOPES. H.V.; Novos antibióticos na prática hospitalar e ambulatorial. São Paulo, Ed. Office, 2000.

9. MIRANDA,V.C. Identificação de microrganismos resistentes ao tratamento endodôntico, com especial referencia aos Estreptococos. Revista Faculdade de Odontologia Araraquara. v. 3, n.1, p.7395, jan/jun. 1969.

10. NODA, M. et al. Antibiotic susceptibility of bacteria detected from the root canal exudate of persistent apical periodontitis. Journal of Endodontics. v.26,n.4, p. 221224, April 2000.

11. NORD,C.F. et al. Suscebility of haemolytic oral Enterococci to eight antibiotics in vitro. Acta Odontologica

Scandinavica. v.13, p.395-399, 1973.

14. MAIA FILHO,ET;RIZZI MAIA,CC;BASTOS,ACSC;NOVAIS,T MG; Efeito antimicrobiano “ in vitro" de diferentes medicações endodônticas e própolis sobre Enterococcus faecalis; RGO, Porto Alegre, v. 56, n.1, p. 21-25, jan./mar. 2008.

15.OLIVEIRA, G.A. et al; Enterococcus sp: Importância Clínica, Fatores de Virulência, Resistência aos Antimicrobianos e Diagnóstico Laboratorial. Laes \& Haes, ano 22, $\mathrm{n}^{\mathrm{o}}$ 131, pg. 88-112, junho/julho 2001.

16. SANTOS FILHO, LAURO: Manual de Microbiologia Clínica, João Pessoa: Ed. Universitária, 1996.

17. WEINE F.S., Tratamento Endodôntico, $5^{\circ}$ ed São Paulo:Ed Santos, 1998.

18. ZEBRAL, A.A.;PINTO, E. C. Estreptococos do Grupo Enterococos em Canais Dentários Infectados e sua Sensibilidade a Antibióticos e Quimioterápicos. Odontólogo Moderno. v. 21, n.2, abr/jun, 1994.

19. ZEBRAL, A.A. A Flora Bacteriana Anaeróbica Facultativa de Canais Dentários Infectados e sua Sensibilidade "In Vitro" a Alguns Antibióticos e Sulfonamidas. Odontólogo Moderno. v. 15, n.2, mar. 1988. 